\title{
Relationship between Relative Humidity and the Dew Point Temperature in Abuja, Nigeria
}

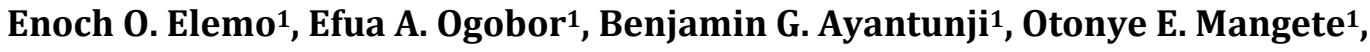

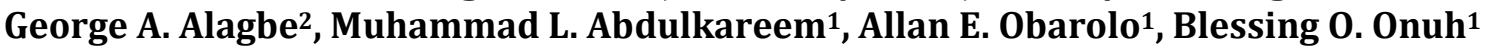 \\ ${ }^{1}$ Physical and Life Science Department, National Space Research and Development Agency, Abuja, Nigeria \\ ${ }^{2}$ Department of Pure and Applied Physics, Ladoke Akintola University of Technology, Ogbomoso, Oyo State, Nigeria \\ Email: enochelemo@yahoo.com
}

How to cite this paper: Elemo, E.O., Ogobor, E.A., Ayantunji, B.G., Mangete, O.E., Alagbe, G.A., Abdulkareem, M.L., Obarolo, A.E. and Onuh, B.O. (2021) Relationship between Relative Humidity and the Dew Point Temperature in Abuja, Nigeria. Open Access Library Journal, 8: e8086.

https://doi.org/10.4236/oalib.1108086

Received: October 17, 2021

Accepted: December 21, 2021

Published: December 24, 2021

Copyright $\odot 2021$ by author(s) and Open Access Library Inc.

This work is licensed under the Creative Commons Attribution International License (CC BY 4.0).

http://creativecommons.org/licenses/by/4.0/

\begin{abstract}
The analysis of the trend in the Relative humidity and Dew point temperature, together with the assessment of the statistical significance between the two parameters received great attention due to its importance to global warming and climate change. The role that the Atmospheric water vapor plays as a greenhouse gas makes it one of the most significant determinants in the discussions of weather and climate. In the current study, the relationship between relative humidity and Dew point temperature at a location in the northern part of Nigeria (Abuja) for a whole year was analyzed. The results showed a very strong linear relationship in the two parameters especially in the dry season. The results also revealed a unique characteristic in the Dew point Temperature values of June, July and August that appeared at this station. The role the movement of the Inter-Tropical Convergence Zone ITCZ played in the results was also discussed.
\end{abstract}

\section{Subject Areas \\ Atmospheric Sciences}

\section{Keywords}

Relative Humidity, Dew Point Temperature, Greenhouse Gas, Linear

Relationship, Nigeria, the Inter-Tropical Convergence Zone ITCZ

\section{Introduction}

It is a known fact that almost all area of human endeavours is affected by the weather. The knowledge of the prevailing conditions of the atmosphere of a place helps in the study of the weather of the place. One of the most important 
determinants of the state of the Weather and Climate of the Earth is the Atmospheric water vapour. The corresponding large amount of energy needed as water changes from one (gaseous or liquid or solid) phase to another, together with its role as a greenhouse gas, makes Atmospheric water vapour very important in Earth's weather and climate [1]. The water vapour in the atmosphere is expected to increase due to global warming, thereby leading to significantly high anthropogenic sources in Climate change [2]. Hence, monitoring of the changes in the atmospheric water vapour content as a means of validating the large water vapour feedback of the various climatic models and as a result of global warming becomes imperative [3]. Relative humidity $(\mathrm{RH})$ can be described as the amount of water vapour in an air sample [1], which directly affects the visibility of the atmosphere. It also plays a prominent role in the formation of fog, clouds and smog [4]. Atmospheric humidity is known to be a very important element in determining the geographical distribution of precipitation and its peak intensity. Its effect is also seen in the area of biosphere and surface hydrology. Relative humidity is known to be a function of temperature and absolute concentration of water vapour.

Great importance has been given to dew point due to the fact that it is seen as the measure of the state of the atmosphere in as much that it tells how much water vapour is present in it. The dew point temperature of the water vapour is the temperature at which the water vapour in the air begins to evaporate or condense simultaneously at the same rate. Dew point temperature is the temperature at which the water vapour presented in the air condenses into water droplets or dew at constant air pressure. This occurs according to [5] when the temperature at actual vapour pressure and the saturation vapour pressure is equal. Dew point is widely regarded as a highly recommended tool for forecasting rain and the probability of thunderstorms [5]. Though dew point and relative humidity are tools used in prognostications of weather and also to express the amount of moisture in the air, they are actually different. While Dew point shows the moisture level in the air, Relative humidity reveals the percentage of the degree of saturation of the air. This leads to the conclusion that: the higher the dew point, the more moisture in the air and vice versa. The closer the dew point is to the actual air temperature, the more humid the air becomes.

Any alteration or changes in one of weather vagaries could invariably lead to changes in others. [6] shows that the dew point temperature and relative humidity are accepted and used as indicators of the amount of moisture in the air. [7] [8] also revealed that the relative humidity is a highly sensitive parameter that has become a measure of the thermal discomfort levels of humans and showed noticeable impacts on the performance of metals, electrical devices and etc. [9] however showed that the relative humidity is influenced by the combination of various meteorological parameters such as solar radiation, dew point temperature and ambient temperature. [10] showed that having a relative humidity value of more than $80 \%$ invariably leads to uneasiness on the skin due to the unique 
characteristics of the surface of the skin and having a relative humidity of $100 \%$ creates muggy conditions. [11] showed that relative humidity is used in forecasting the rain and the probability of thunderstorms. [11] also revealed that having a Dew point greater than $60^{\circ} \mathrm{C}$ at lower atmosphere is a clear indication of intense thunderstorms.

\section{Methodology}

Weather vagaries such as the UV index, temperature, dew point, humidity, wind speed, precipitation rate etc. were measured with an automatic meteorological weather station, Davis Vantage Pro 2 Wireless. The Davis Vantage Pro 2 records atmospheric parameters in one package called the integrated sensor suite (ISS). The station was installed at Wuse 2 , Abuja $\left(9.08^{\circ} \mathrm{N}, 7.48^{\circ} \mathrm{E}\right)$, Nigeria, at an elevation of approximately $493 \mathrm{~m}$ above sea level. The data was saved on the data logger affixed to the Davis vantage Pro2 console; the data logger also provides an interface for direct access to the weather station recorded data. The 6510 data logger USB variant was used alongside the WeatherLink software to store the data on a local computer and also to upload the data to the WeatherLink cloud. The sampling was done at 5 mins and it was averaged to one hour for the sake of this study.

\section{Results and Discussions}

The rainfall pattern for each month of the year 2020 can be seen in Figure 1. It can be seen that the rain started in the month of March (smallest in terms of volume and just two days) till October (12 days) with September having the highest number of days of rainfall and in terms of volume of rainfall too. This is in agreement with [12], which stated that precipitations increase (rainfall peak) when the ITCZ is in the northern-most position.

Figure 2 shows the daily mean in the dew point temperature and the relative humidity (RH) for each month of the year 2020. In January, both parameters showed an extremely similar trend throughout the whole days of the month. The Peak of both parameters occurred on the same day (day 12) and the least was seen on day 25 and day 30 . The Peak of the relative humidity was at $51 \%$, while the Peak of the Dew point temperature (D) was at $18^{\circ} \mathrm{C}$. The month of February showed the same trend in the two parameters. Both Peak and least occurred on the same day (day 18 and 11 respectively). There was a reduction in the values of both parameters, leading to reduced peaks $\left(\mathrm{RH}=33 \%\right.$ and $\left.\mathrm{D}=13^{\circ} \mathrm{C}\right)$.

The month of March (only 17 days data were available) still showed the same trend in both parameters as seen in January, in that, the peak and the depressions occurring the same day. One major difference in this month is that the difference in the values of the two parameters is much larger than the two previous months, as seen in the graph. The Peak of the Relative humidity increased by $212 \%$ when compared to the previous month. While that of the Dew point temperature increased by $176.9 \%$ when compared with the previous month. 

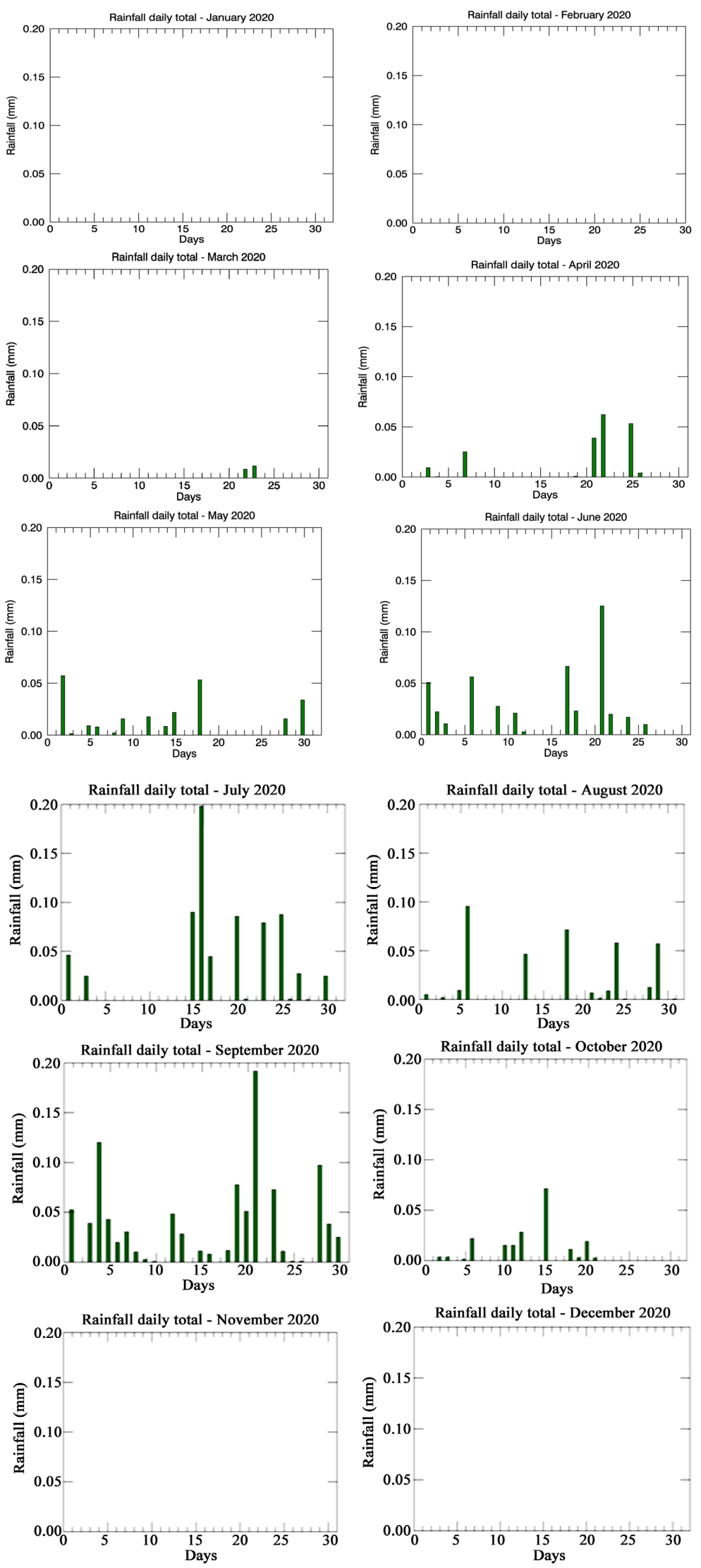

Figure 1. Rainfall pattern for the year 2020. 


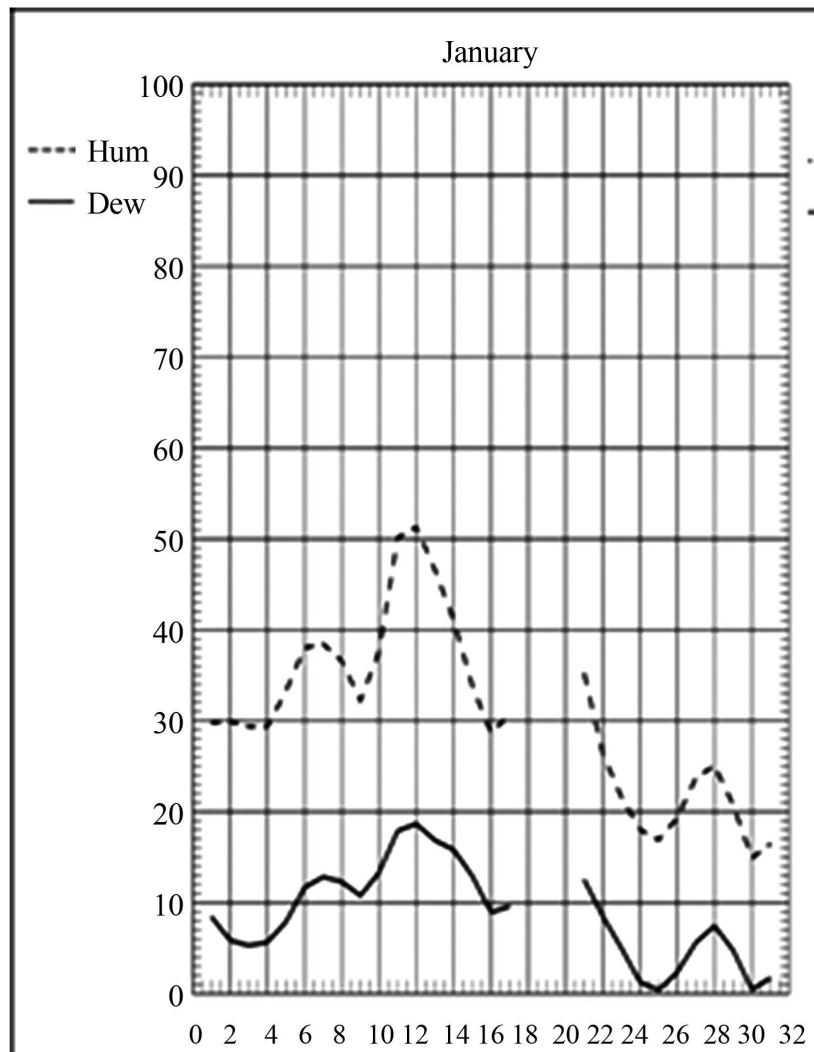

Day

2020

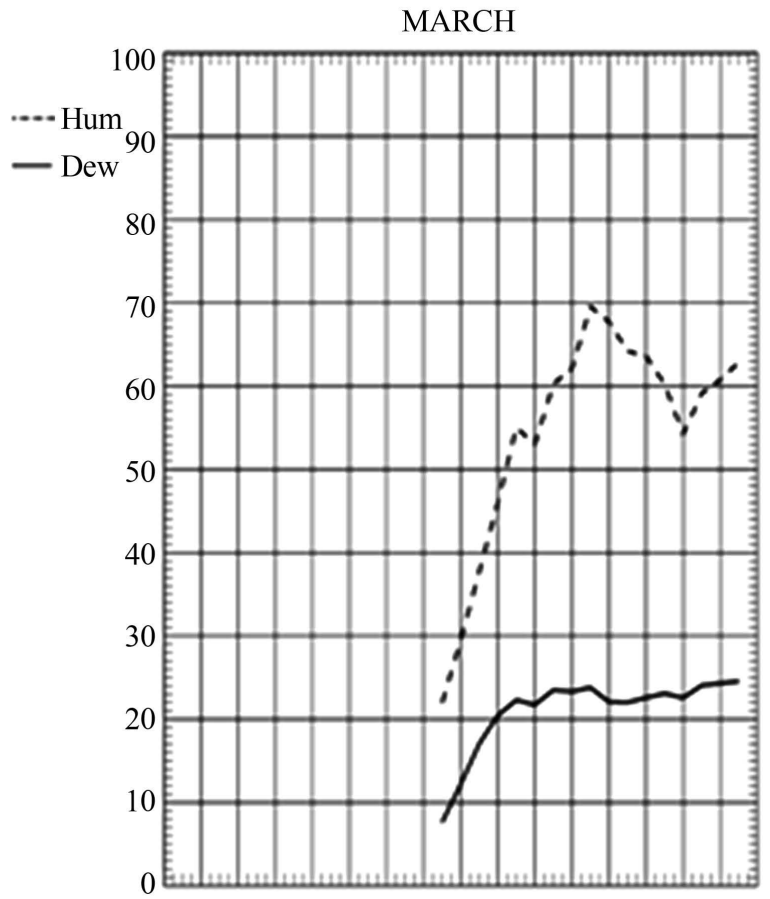

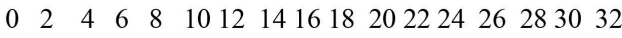
Day

2020

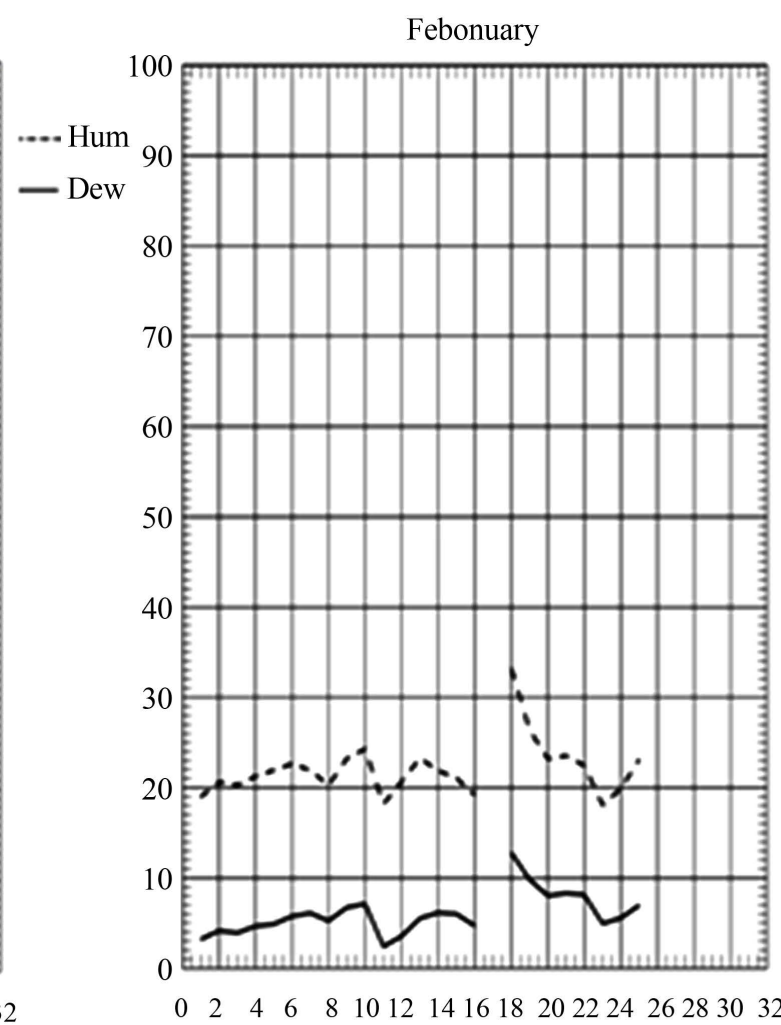

Day

2020

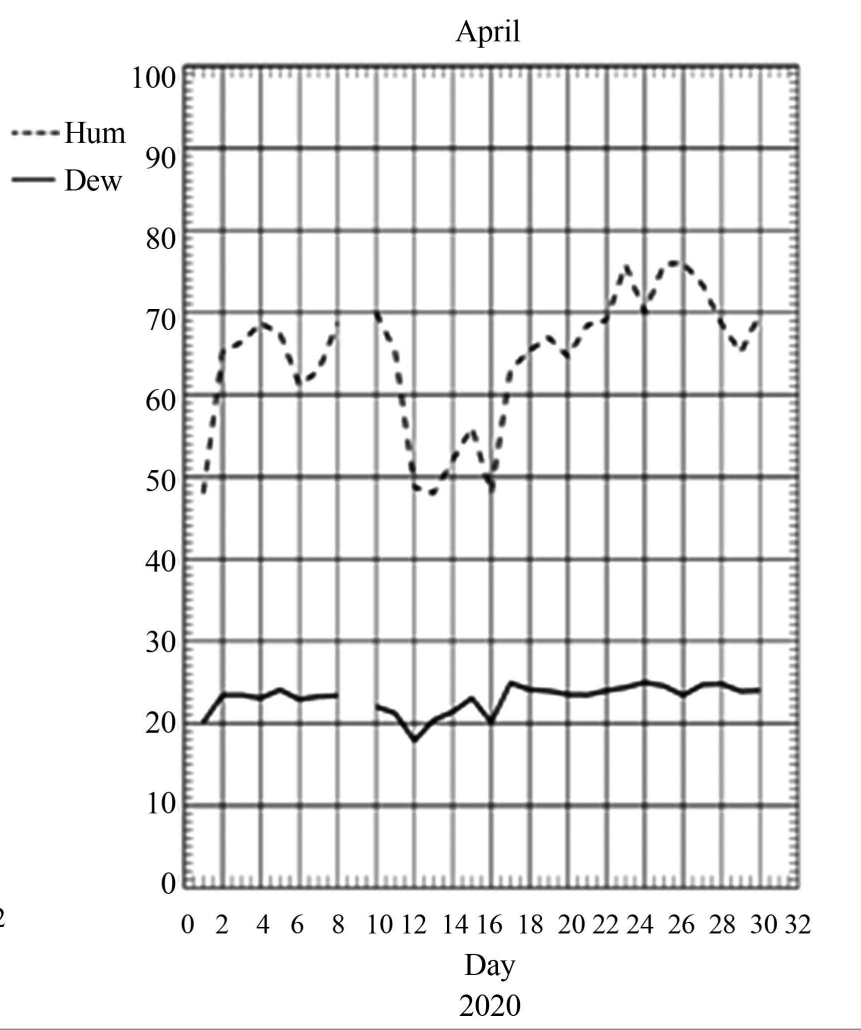



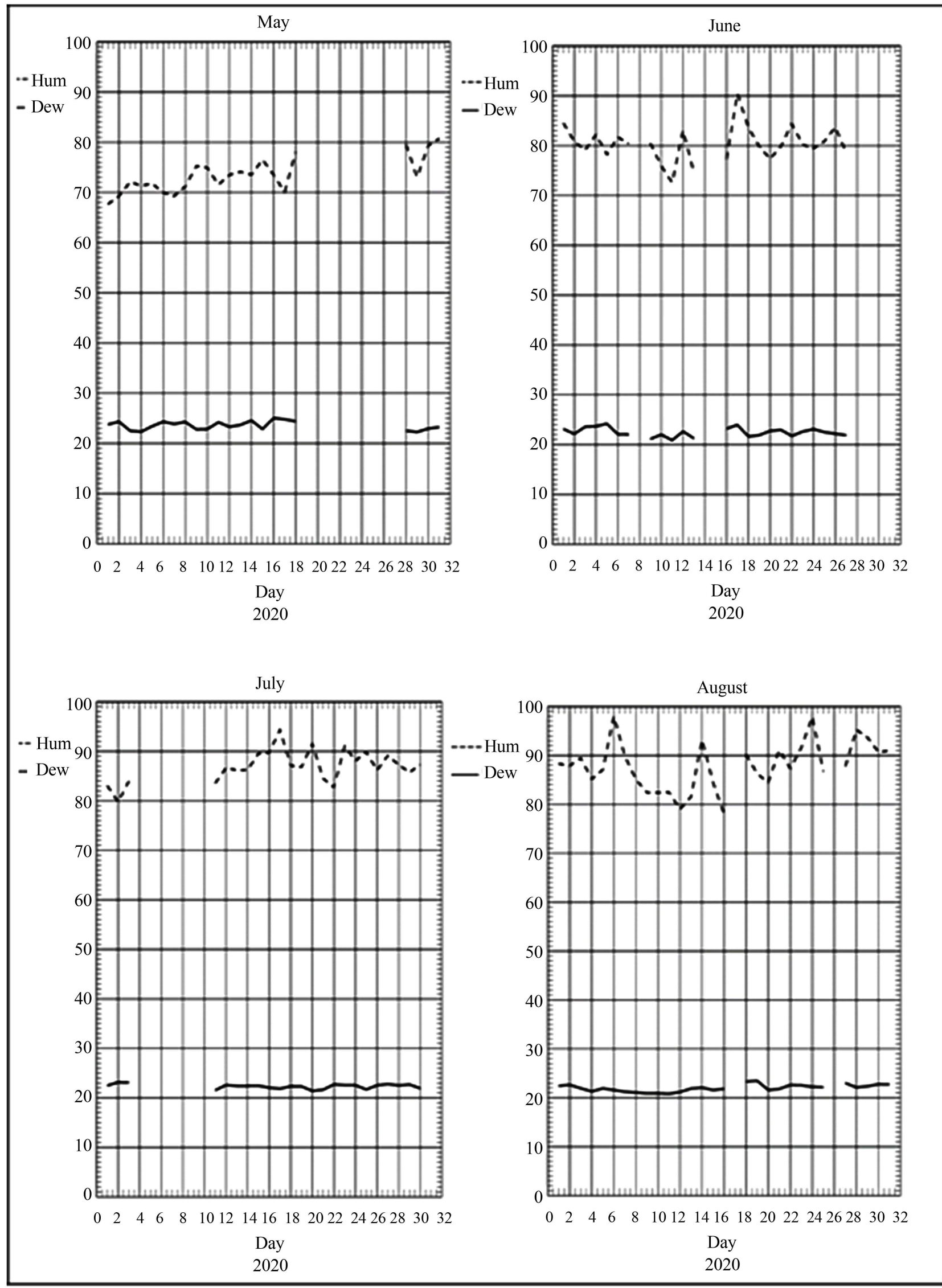


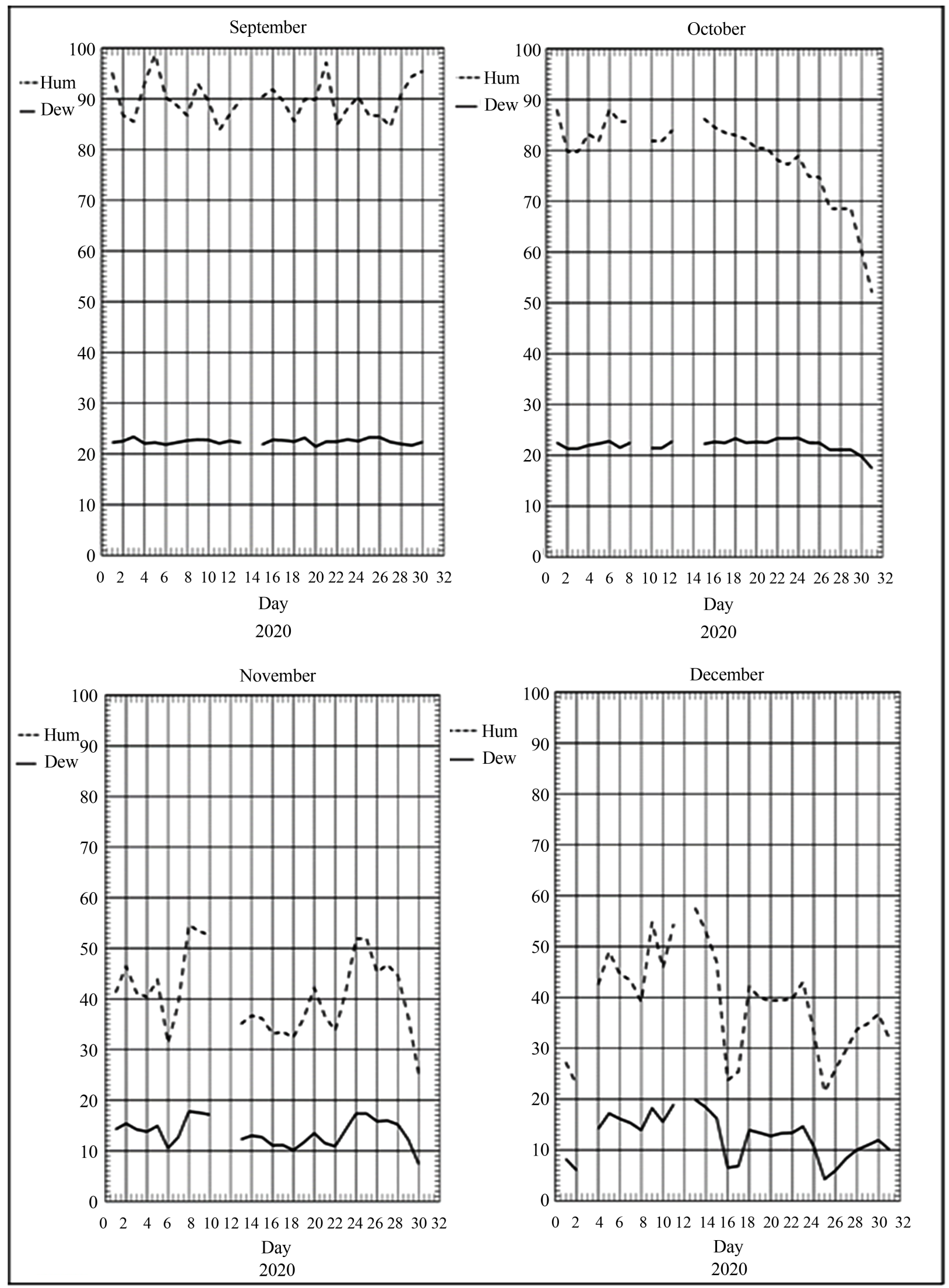

Figure 2. Variation of the relative humidity and dew point temperature each month of the year 2020. 
The month of April had both parameters showing more of a similar trend (when one is high, the other is high too and vice versa) than an opposite trend. The "difference" between the two parameters also increased further from the previous month (March). The month of May showed the two parameters to be clearly opposite to each other from the beginning of the month to the end when studied based on the variations in the two (when one is high the other is low and vice versa). This definitely was not the scenario in the first three months. The difference between the two parameters is now far further away from each other when compared with the previous month. The month of June had opposite variations in the two parameters in almost all the days of the month except from day 10 till day 13 . The values of the relative humidity also experienced a strong increase, which led to the difference between the two parameters being wider. Based on the available data, it was clear that the month of July had the two parameters clearly showing opposite variations to each other throughout the whole month when studied based on their variations. Another point to be noted is that the values of the relative humidity increased far more (from March) than the dew point temperature. This led to a further larger difference between the two parameters. The month of August showed that Dew point temperature was almost flat (same) for many days in the month. While the relative humidity increased from last month. The "flatness" on some days started in July but were more pronounced and occurred more in August. On the other hand, the month of September showed more values higher than $90 \%$ in relative humidity than any other month in the year. The dew point temperature also showed very little "flatness" but far less than the month of July. Invariably, the difference in the two parameters was highest in this month. The month of October experienced both opposite and similar trends in the two parameters. There was a more similar trend than the opposite. There was also a little "flatness" in this month. The difference in the two parameters was reduced for the first time in several months. The month of November had a full returned to the same trend in the two parameters. Both exhibited the same variations (same highs, same lows) throughout the days of the whole month. The difference in the two parameters reduced drastically. The reduction was far bigger than that of September to October. The peak of the relative humidity in November reduced by $160 \%$ from the month of October. While that of the dew point temperature reduced by $127.7 \%$. The month of December had the same trend as November as both had the same high and low variations.

According to [12] [13], the months of the dry season in the Northern part of Nigeria where the station is between October and April. That of the wet or rainy season is between May and September. The values of both parameters are higher during the rainy season than during the dry season. This is to be expected according to [6] [14], which states that the dew point reveals how much moisture is in the air, whereas, the relative humidity is known as a percentage that indicates how saturated the air is. In other words, the higher the dew point, the more moisture that is present in the air and vice versa. The months of June till Octo- 
ber had lots of days that the values of the relative humidity were $80 \%$ and above. There might likely be lots of uneasiness of the skin as a result of this according to [10]. The two parameters (Relative humidity and dew point temperature) showed a similar trend every day during the months of January, February, March, November and December and almost full same trend (both same and opposite but more of same) in October and April. The months with almost full same trend were months that had rain even though they are naturally classified as dry season in the northern part of the country. The months in the wet season showed both (same and opposite) trends but whether it is more of the same or opposite trend depends on the volume of the rain that month. When there are more days of rainfalls in any month then there will be more of the opposite trend and vice versa. On the other hand, the month the rain started (March) was the month that the difference in the values of the two parameters became large, and became even larger in some other months as the volume of the rainfall increases. This is in agreement with [13] [15] [16] which stated that the Inter-Tropical Convergence Zone ITCZ is at the southernmost position in Nigeria (location of station) around January and February during which the influence of the north-east winds prevails during the season (dry). The rainy season starts in March and the ITCZ gets to the northernmost position in July. The north-south migration of the ITCZ location over Nigeria leads to seasonal patterns. The coming of the rainfall brought about stronger effects on the relative humidity more than the Dew point temperature as revealed by the very high values of the relative humidity during the wet season. This is in agreement with [5] which states that the dew point temperature indicates just how much moisture that is present in the air, whereas the relative humidity is a percentage that indicates just how saturated the air is. This simply means, the higher the dew point, the more moisture that is in the air and vice versa. [17] shows that the relative humidity is a function of the Air temperature and the absolute water vapour concentration. Therefore, a change seen in the relative humidity may be accounted for by a corresponding change seen in the dew point temperature.

Another important piece of information showed by this work is that the rate at which absorption of moisture took place at the location was stronger from February to March (Peak of the Dry season) than from October to November (beginning of another dry season). This result was due to the percentage increase in both parameters from February to March and from October to November. On the other hand, the months of July and August, September and October 2020 showed a characteristic that was unique to these four months alone. The dew point temperature had a flat (same) value for some days in those months: with October being the least, then September, then July, with August having most. This might be as a result of the position of the ITCZ and the Sun according to [12] [13] [15] [16]. Having the ITCZ in the northernmost position in July creates two phenomena: The precipitation (rainfall) reduces in the south of Nigeria, but increases in the North. Thereby, leading to a term called August break in the south but rainfall peak in the North. However, [12] revealed that the tempera- 
ture measurements in Nigeria rise as the Sun crosses the Equator and moves northward in the month of March making the air temperature in March and April to be very high. This however reduces as the Sun moves back southward leading to another high set of temperatures in October and November. The combination of the position of the Sun and that of the ITCZ at the same time might be the reason. This is because according to [17], Relative humidity is a function of the temperature and absolute Water vapour concentration (dew point temperature). The paper by [9] also showed that the relative humidity is influenced by the combination of various meteorological parameters such as solar radiation, dew point temperature and ambient temperature. The rainy season months in this work had a relative humidity of $70 \%$ and above which is in agreement with a postulate by [11], which says that it is likely to rain at any location when the relative humidity is $70 \%$ and above.

Figure 3 shows the mean of the Dew point Temperature and the relative humidity at the station. The lowest mean of both parameters occurred in the same month of February. This means both parameters had the same "trigger" and both responded in the same way. However, the maximum value for Dew point temperature occurred in May but that of the relative humidity occurred in September. The graph of the Mean of the Dew point temperature showed a steady increase from February up to May and then decreased slightly up to August, after an increase in September, it decreased till December. That means, even though the volume of rainfall increased, the Dew point temperature increased first till May, then, kept reducing slightly till August before eventually decreased. On the other hand, the mean of the relative humidity showed consistent increasing values from March up till September before it now decreased till the end. That means the more rainfall, the stronger the relative humidity, whereas the same cannot be said of dew point temperature.

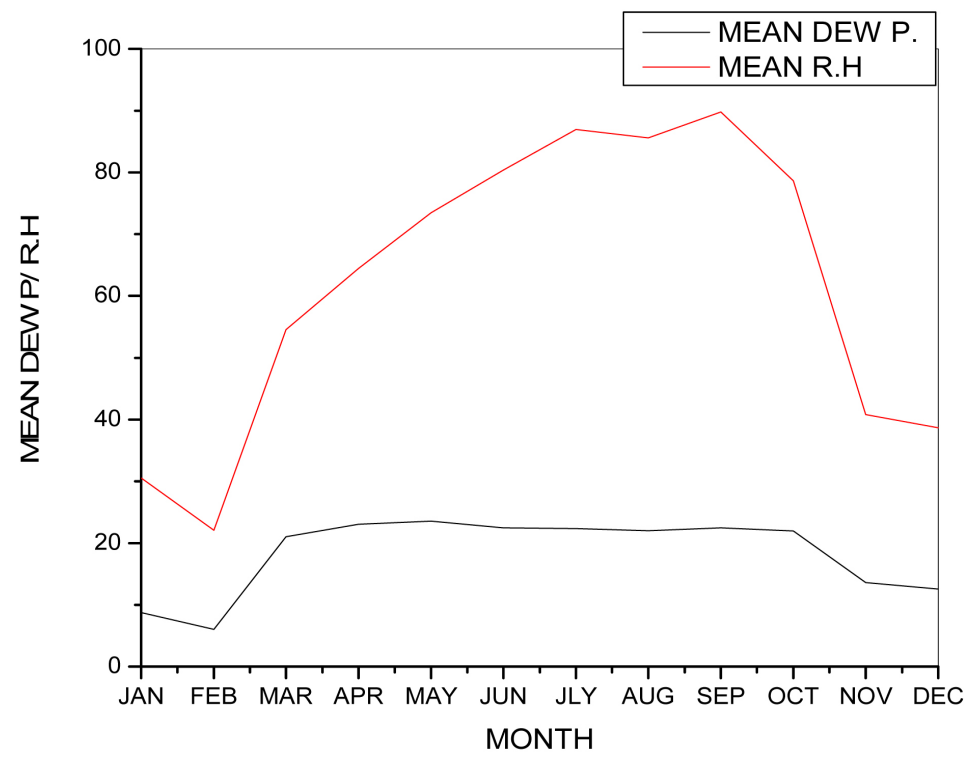

Figure 3. The mean of the dew point temperature and the relative humidity at the station. 

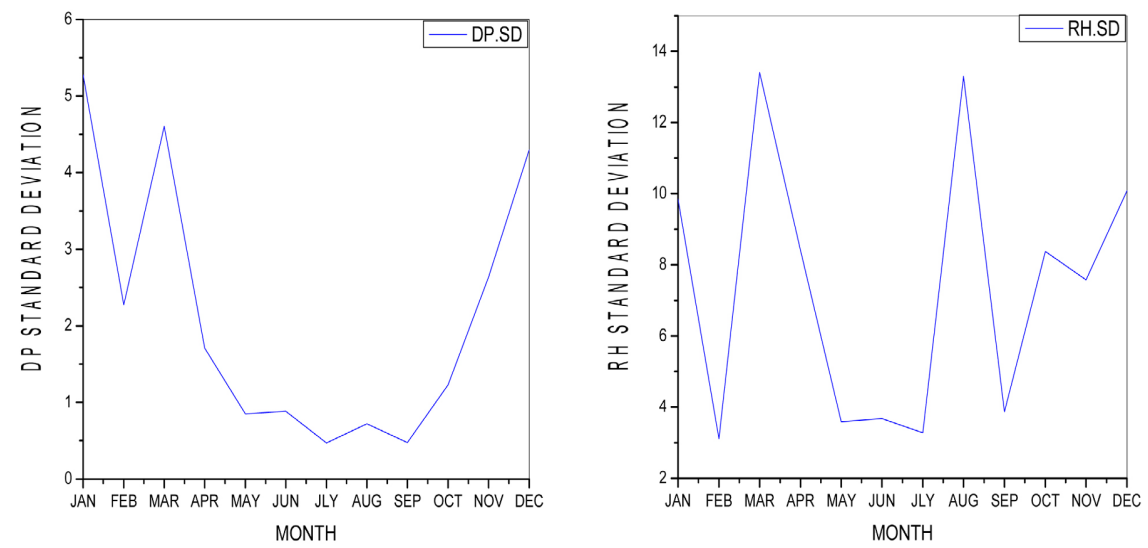

Figure 4. The standard deviation of the dew point temperature and the relative humidity station.

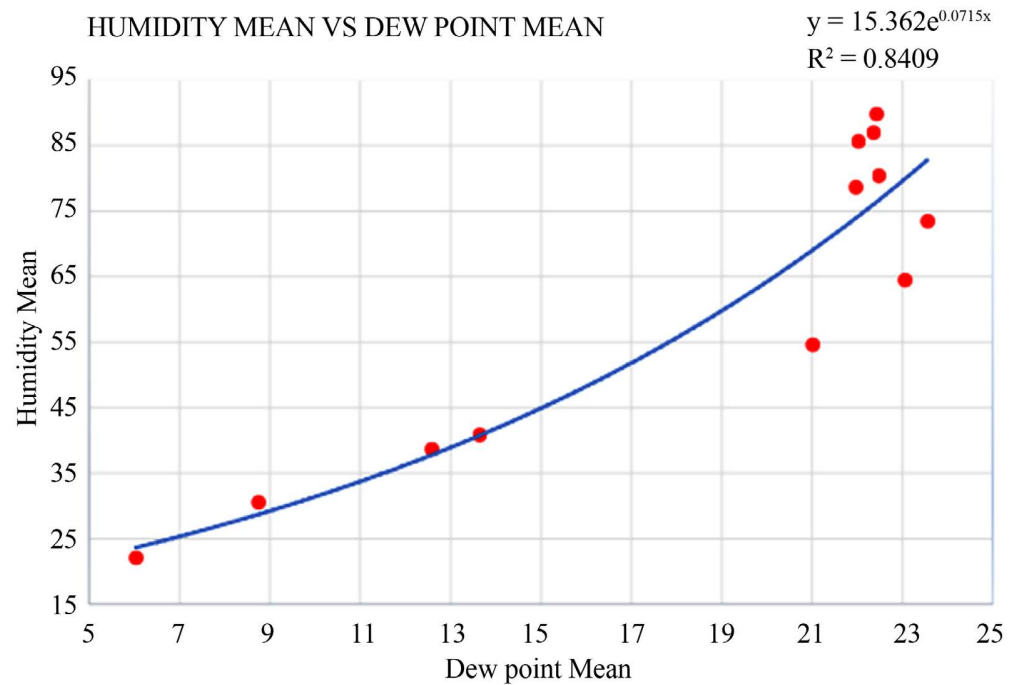

Figure 5. The relationship between relative humidity and dew point temperature of the station.

Figure 4 shows the standard deviation of the two parameters across the months of the year. It was clear that there was a strong enhancement from February to March in the standard deviation of Dew point temperature. The Dew point temperature also has a slight enhancement from May to June and from July to August. The standard deviation of the Relative humidity had a very strong enhancement from February to March, a slight enhancement from May to June, a very strong enhancement from July to August and an enhancement from September to October. All these clearly show the impact of the rainy season was stronger on relative humidity than on Dew point temperature.

Figure 5 shows the relationship between relative humidity and Dew point temperature.

Figure 3 and Figure 5 show that the relationship can be said to be a linear relationship with a significant coefficient of determination $\left(\mathrm{R}^{2}\right)$ of 0.9183 . The result is in agreement with works done by [5] [6] [14]. 


\section{Conclusion}

This paper analyzed the relationship that exists in the Relative humidity and Dew point temperature at a location in Abuja using a whole year (2020) data. The location of the station throws up some very interesting facts in course of our analysis. Some of the important role that the Inter-Tropical Convergence Zone (ITCZ) and the movement of the Sun play in the state of the atmosphere of the place was also shown. The fact that the values of the Dew point Temperature were never gotten to $30^{\circ} \mathrm{C}$ throughout the whole year, made it possible to say that the location was not a place at all for intense thunderstorms according to [11].

\section{Acknowledgements}

Special appreciation goes to Mr Ghatikar (https://www.wunderground.com/dashboard/pws/IABUIA3) for making the station available for us to use its data.

\section{Conflicts of Interest}

The authors declare no conflicts of interest.

\section{References}

[1] Abu-Taleb, A.A., Alawneh, A.J. and Smadi, M.M. (2007) Statistical Analysis of Recent Changes in Relative Humidity in Jordan. American Journal of Environmental Sciences, 3, 75-77.

[2] Willett, K.M., Gillett, N.P., Jones, P.D. and Thorne, P.W. (2007) Attribution of Observed Surface Humidity Changes to Human Influence. Nature, 449, 710-713. https://doi.org/10.1038/nature06207

[3] Dai, A. (2006) Recent Climatology, Variability, and Trends in Global Surface Humidity. Journal of Climate, 19, 3589-3606. https://doi.org/10.1175/JCLI3816.1

[4] Elliott, W.P. and Angell, J.K. (1997) Variations of Cloudiness, Precipitable Water and Relative Humidity over the United States. Geophysical Research Letters, 24, 4144. https://doi.org/10.1029/96GL03616

[5] Tawhida, A.Y. and Hisham, M.M.T. (2013) The Relationship between Relative Humidity and the Dew point Temperature in Khartoum State, Sudan. Journal of Applied and Industrial Sciences, 1, 20-23.

[6] Lawrence, M.G. (2005) The Relationship between Relative Humidity and the Dewpoint Temperature in Moist Air: A Simple Conversion and Applications. Bulletin of the American Meteorological Society, 86, 225-234.

https://doi.org/10.1175/BAMS-86-2-225

[7] Eludoyin, O.M., Adelekan, I.O., Webster, R. and Eludoyin, A.O. (2014) Air Temperature, Relative Humidity, Climate Regionalization and Thermal Comfort of Nigeria. International Journal of Climatology, 34, 2000-2018.

https://doi.org/10.1002/joc.3817

[8] Gornicki, K., Winiczenko, R., Kaleta, A. and Choinska, A. (2017) Evaluation of Models for the Dew Point Temperature Determination: Technical Sciences, 20, 241-257. https://doi.org/10.31648/ts.5425 
[9] Chabane, F., Moummia, N. and Brima, A. (2018) Forecast of Relationship between a Relative Humidity and a Dew Point Temperature. Journal of Power Technologies, 98, 183-187.

[10] Tanabe, S.I. and Kimura, K.I. (1994) Effect of Air Temperature, Humidity, and Air Movement on Thermal Comfort under Hot and Humid Conditions. ASHRAE Transactions, 100, 953-969.

[11] Yousif, T.A. and Tahir, H.M. (2013) The Relationship between Relative Humidity and the Dew Point Temperature in Khartoum State, Sudan. Journal of Applied and Industrial Sciences, 1, 20-23.

[12] Salau, O.R. (2017) The Links between Variations in Climate Patterns and ITCZ Position over Nigeria. World Scientific News, 87, 191-204.

[13] Adler, R.F., Huffman, G.J., Chang, A., Ferraro, R., Xie, P., Janowiak, J., Rudolf, B., Schneider, U., Curtis, S., Bolvin, D., Gruber, A., Susskind, J. and Arkin, P. (2003) The Version 2 Global Precipitation Climatology Project (GPCP) Monthly Precipitation Analysis (1979-Present). Journal of Hydrometeorology, 4, 1147-1167. https://doi.org/10.1175/1525-7541(2003)004\%3C1147:TVGPCP\%3E2.0.CO;2

[14] Ukhurebor, K.E., Azi, S.O., Abiodun, I.C. and Enoyoze, E. (2017) Approximation of the Dew Point Temperature Using a Cost-Effective Weather Monitoring System. Physical Science International Journal, 14, Article No. PSIJ.32862.

[15] Ododo, J.C. (1994) New Models for the Prediction of Solar Radiation in Nigeria. Proceedings of the 2 nd OAUISTRC Conference on New, Renewable and Solar Energies, Bamako, 16-20 May 1994.

[16] Udo, I.A. and Okujagu, C.U. (2014) Assessment of Inter-Tropical Convergence Zone (ITCZ) Impact on Precipitation in Six Locations in Nigeria. International Journal of Science and Research, 3, 2736-2739.

[17] Van Wijngaarden, W.A. and Vincent, L.A. (2003) Trends in Relative Humidity in Canada from 1953-2003. Report Prepared for Climate Research Branch, Meteorological Service of Canada, Toronto. 